Thorax, 1977, 32, 121-128

\title{
Quantitative structural study of pulmonary circulation in the newborn with aortic atresia, stenosis, or coarctation
}

\author{
SHEILA G. HAWORTH AND LYNNE REID
}

From the Department of Experimental Pathology, Cardiothoracic Institute, Brompton Hospital, London SW3

Haworth, Sheila G. and Reid, Lynne (1977). Thorax, 32, 121-128. Quantitative structural study of pulmonary circulation in the newborn with aortic atresia, stenosis, or coarctation. Study of the structural features of the pulmonary circulation in various types of congenital heart disease makes it possible to correlate function and structure in the fetal and newborn lung. We applied quantitative morphometric techniques to the injected and inflated lungs of newborn infants who had died with obstruction to left ventricular outflow from aortic atresia, stenosis, or coarctation. The structure and development of the pulmonary circulation was judged by the number of arteries and veins and their size and wall structure, with particular attention to vessels within the respiratory unit. The study established for the first time that the structure of the pulmonary circulation is modified by the antenatal abnormalities in blood flow that occur through the heart and great vessels in the presence of congenital heart disease. Fetal multiplication of intra-acinar arteries in aortic atresia and stenosis is increased as also is the muscularity of both pre- and intra-acinar arteries and veins, muscle extending into smaller and more peripheral vessels than is normal at birth. When the pulmonary circulation is normal before birth but arterial pressure and flow are abnormally increased at birth, as in coarctation with patent ductus and ventricular septal defect, an increase in arterial diameter and muscularity is apparent within the first week of life.

Since recent surgical advances have made more types of congenital heart disease amenable to surgery at an early age interest in the behaviour of the fetal circulation in the presence of congenital heart disease has increased. For example, Rudolph et al. (1974) have studied the effect on the lamb fetal circulation of banding, in utero, either of the great vessels to produce experimentally aortic or pulmonary stenosis. If performed early in fetal life this operation produces structural changes in the heart similar to those found in the human: the haemodynamic changes can be measured while the animal is still in utero. These studies have not included an assessment of lung development.

Previous reports do not agree on the structural changes found in the pulmonary vessels of infants dying with underdevelopment of the left heart. Wagenvoort and Edwards (1961) described an increase in the number of muscular pulmonary arteries at the lung periphery, and Naeye (1962), measuring medial area, reported an increase in wall thickness of individual pulmonary arteries. Ferencz and Dammann (1957) emphasised that medial hypertrophy in such cases was more severe than that seen in septal defects. In contrast, Rudolph (1974) reported four cases of hypoplastic left heart syndrome, two attributed to Thomas, and described the arteries at birth as dilated and relatively thin walled. The pulmonary veins also show increased muscularity (Samuelson et al.. 1970) and often resemble arteries (Wagenvoort, 1970). In severe coarctation of the aorta with patent ductus arteriosus Naeye (1961) demonstrated an increase in pulmonary arterial muscle, and considered that this had developed in utero.

The present report describes in detail the structural features of the pulmonary circulation in a small series of newborn infants with lesions obstructing the left ventricular outflow-that is, 
aortic atresia, stenosis, and coarctation. Quantitative morphometric techniques were applied to the injected and inflated lung in order to describe the development of the pulmonary circulation as judged by vessel number, size, and structure, particular attention being given to the vessels within the respiratory unit of lung, the acinus. The structural changes in the pulmonary circulation were related so far as possible to haemodynamic features either as thought to be present in utero or as measured after birth.

\section{Patients and methods}

\section{CLINICAL FEATURES}

Lung structure was examined in six patients: two with aortic atresia, two with aortic stenosis, and two with coarctation of the aorta and patent ductus arteriosus (PDA) with ventricular septal defect (VSD). The two cases of aortic atresia (cases 1 and 2) and one of the cases of aortic stenosis (case 3) presented during the first three days of life and died by the third day (Table 1). The second case of aortic stenosis (case 4) presented on the tenth day of life and died at 21 days. Physical findings were similar in these four cases-tachypnoea, peripheral pulses reduced in volume in upper and lower limbs, and peripheral oedema. One infant with aortic atresia had a continuous murmur in the left infraclavicular region (case 1) and the other a mid-systolic murmur at the upper left sternal edge (case 2). One of the infants with aortic stenosis had no murmur (case 3 ) and one had a short ejection murmur (case 4). In all four cases the electrocardiogram showed right ventricular hypertrophy, with either a QR complex or a 'pure' $R$ wave exceeding $10 \mathrm{~mm}$ in leads V4 $R$ and $\mathrm{V} 1$ as compared with an $\mathrm{R}$ wave of $5 \mathrm{~mm}$ or less in V6. The chest radiographs showed pulmonary oedema and cardiac enlargement, the cardiothoracic ratio exceeding $63 \%$ in all infants.

Cardiac catheterisation was not performed in the two cases of aortic atresia. In the infants with aortic stenosis the gradient across the aortic valve was $4.39 \mathrm{kPa}(33 \mathrm{mmHg})$ in case 3 and $9.31 \mathrm{kPa}$ $(70 \mathrm{mmHg}$ ) in case 4 and pulmonary arterial pressure was greater than systemic pressure in both. Left ventriculography in case 3 showed a small left ventricle. Surgical correction was attempted in both cases but death occurred during operation in case 3 and eight days after operation in case 4.

One of the two infants with coarctation of the aorta (case 5) presented on the third and died on the fifth day of life, and the other presented at 16 days and died one day later after resection of the coarctation and banding of the pulmonary artery. The electrocardiogram showed right ventricular hypertrophy in case 5 and left ventricular hypertrophy in case 6 . In both cases the chest radiograph showed cardiac enlargement with a cardiothoracic ratio greater than $73 \%$. Pulmonary vascular markings were normal in case 5 but increased in case 6 . In both infants the pulmonary arterial pressure at cardiac catheterisation was at systemic level, the ductus arteriosus was patent, and angiography demonstrated coarctation of the aorta and PDA with VSD.

In all six cases the diagnosis was confirmed at necropsy. In the two cases of aortic atresia the left ventricle was very small and in the two cases of aortic stenosis smaller than normal: all four had endocardial fibroelastosis of the left ventricle. In one case of aortic atresia (case 2) a secundum atrial septal defect was present and in the other three cases the foramen ovale was enlarged and circular. In the cases with coarctation of the aorta and PDA an infracristal VSD was also present. It

Table 1 Summary of pathological findings

\begin{tabular}{|c|c|c|c|c|c|c|c|c|}
\hline & \multirow{2}{*}{$\begin{array}{l}\text { Case } \\
\text { No. }\end{array}$} & \multirow{2}{*}{$\begin{array}{l}\text { Age at } \\
\text { death } \\
\text { (days) }\end{array}$} & \multicolumn{2}{|l|}{ Arterial size } & \multirow{2}{*}{$\begin{array}{l}\text { Arterial } \\
\text { No. }\end{array}$} & \multirow{2}{*}{$\begin{array}{l}\text { Arterial } \\
W T\end{array}$} & \multirow{2}{*}{$\begin{array}{l}\text { Peripheral } \\
\text { extension of } \\
\text { arterial muscle }\end{array}$} & \multirow{2}{*}{$\begin{array}{l}\text { Vein } \\
W T\end{array}$} \\
\hline & & & Pre-acinar & Intra-acinar & & & & \\
\hline Aortic atresia & $\begin{array}{l}1 \\
2\end{array}$ & $\begin{array}{l}1 \\
3\end{array}$ & $\stackrel{\uparrow}{\mathbf{N}}$ & $\begin{array}{l}\mathbf{N} \\
\mathbf{N}\end{array}$ & & $\uparrow$ & & $\begin{array}{l}\uparrow \mathbf{A} \\
\mathbf{A}\end{array}$ \\
\hline Aortic stenosis & $\begin{array}{l}3 \\
4\end{array}$ & $\begin{array}{r}3 \\
21\end{array}$ & $\begin{array}{l}\mathbf{N} \\
\mathbf{N}\end{array}$ & $\begin{array}{l}\mathbf{N} \\
\mathbf{N}\end{array}$ & $\uparrow$ & $\uparrow$ & $\uparrow \uparrow$ & $\uparrow \begin{array}{l}\uparrow \mathbf{A} \\
\mathbf{A}\end{array}$ \\
\hline Coarctation & $\begin{array}{l}5 \\
6\end{array}$ & $\begin{array}{r}5 \\
17\end{array}$ & $\uparrow \uparrow$ & $\uparrow$ & $\begin{array}{l}\mathbf{N} \\
\mathbf{N}\end{array}$ & $* \downarrow$ & $\uparrow$ & $\mathbf{N}$ \\
\hline
\end{tabular}

$\mathbf{N}=$ Normal.

$\uparrow=$ Increase above normal, number of arrows indicating degree.

$\downarrow=$ Decrease below normal.

A = 'Arterialisation' (Wagenvoort, 1970).

$\mathbf{W T}=\mathrm{Wall}$ thickness as $\%$ of external diameter.

* = Affecting only arteries $>250 \mu \mathrm{m}$ in diameter. 
was $4 \mathrm{~mm}$ in diameter in case 5 and $3 \mathrm{~mm}$ in case 6; the foramen ovale was patent but not enlarged.

\section{MATERIAL FOR PATHOLOGICAL STUDY}

In cases 1 and 3 the pulmonary arteries to both lungs were injected and in the others the right pulmonary artery and left pulmonary vein. In each lung either the pulmonary arteries or veins were injected with a Micropaque-gelatin suspension at $60^{\circ} \mathrm{C}$ and at a pressure of $100 \mathrm{~cm} \mathrm{H}_{2} \mathrm{O}(1.0 \mathrm{kPa})$ : this injection technique fills and distends all vessels larger than $15 \mu \mathrm{m}$ in diameter. The lungs were then inflated with a buffered formol saline solution at a pressure of $45 \mathrm{~cm} \mathrm{H}_{2} \mathrm{O}(0.45 \mathrm{kPa})$ and allowed to fix: each lung was radiographed and sliced (Davies and Reid, 1970; Hislop and Reid, 1970) and blocks of tissue were selected by a random sampling technique for microscopic examination (Dunnill, 1962).

\section{QUANTITATIVE ANALYSIS OF STRUCTURAL FEATURES OF LUNG}

From the arteriogram the following features can be measured: hilar and intrapulmonary pattern of branching, and the density of background haze which reflects the number of small peripheral arteries (Anderson et al., 1973); apicocaudal lung length; length of posterobasal artery measured along its pathway from hilum to costophrenic angle; and lumen diameter of the arterial pathway to the posterior basal segment measured at the hilum and at $25 \%$ intervals from hilum to pleural surface.

Microscopically the following features of peripheral arterial structure were studied: the external diameter of an individual artery, measured by taking the distance between the external elastic laminae across two diameters; wall thickness, measured from external to internal elastic laminae at the four sites where the measured diameters cut the wall-the mean wall thickness was then calculated. From these measurements

$$
\frac{2 \times \text { wall thickness }}{\text { external diameter }} \times 100=\% \text { wall thickness }
$$

Obliquely sectioned arteries were measured only across the smallest diameter, since this is the true diameter, and at this point the measurement of wall thickness is also the accurate one. The structure of the arterial wall-whether muscular, partially muscular, or non-muscular-is established. The arteries found within a unit area can be grouped by size and structural type and the proportion of each structural type determined within a group of arteries of a given sizedescribed as a 'population count'. When a small artery accompanies a small airway it is also characterised by reference to the type of airway it accompanies. Thus the structure of the artery can be related to airway level and in this way extension of muscle along the arterial pathway is established. The number of arteries and alveoli are counted in the same area of lung section and the results expressed as a ratio to correct for any difference in the degree of inflation in different lungs. The proportion of lung volume occupied by various structures is established by a microscopic point-counting technique (Dunnill, 1962). Increased muscularity is thus apparent from an increased wall thickness as related to size of an artery, or the presence of muscle in arteries which are either smaller or in a more peripheral position along the arterial pathway than is normal.

Since in the first weeks of life the lung is growing rapidly the findings for each patient are compared with those of a normal infant of a similar age.

\section{Results}

The structural features in the pulmonary circulation are summarised in Table 1 . Since in the cases of aortic atresia and stenosis the findings, while similar, were somewhat different from those in the two cases of coarctation and PDA with VSD the results from the two groups of patients are presented separately. Certain features of the arteriogram were similar and normal in all six cases-the pulmonary arterial branching pattern, apicocaudal lung length, and lower lobe artery length.

\section{AORTIC ATRESIA AND STENOSIS \\ Arterial size}

In cases of aortic atresia and stenosis the lumen diameter of preacinar arteries was normal, except in case 1 where it was slightly increased. At the lung periphery external diameter of intra-acinar arteries was in all cases normal.

\section{Number of intra-acinar arteries}

In all four cases the background haze on the arteriogram was denser than normal (Fig. 1), suggesting an increase in the number of peripheral arteries. The proportion of lung volume occupied by arteries as assessed by microscopic point counting was also abnormally high. An increase in number of arteries per unit area of lung explained these findings (Table 2). Because the alveolar number per unit area was normal the alveolar/ arterial ratio was reduced. 

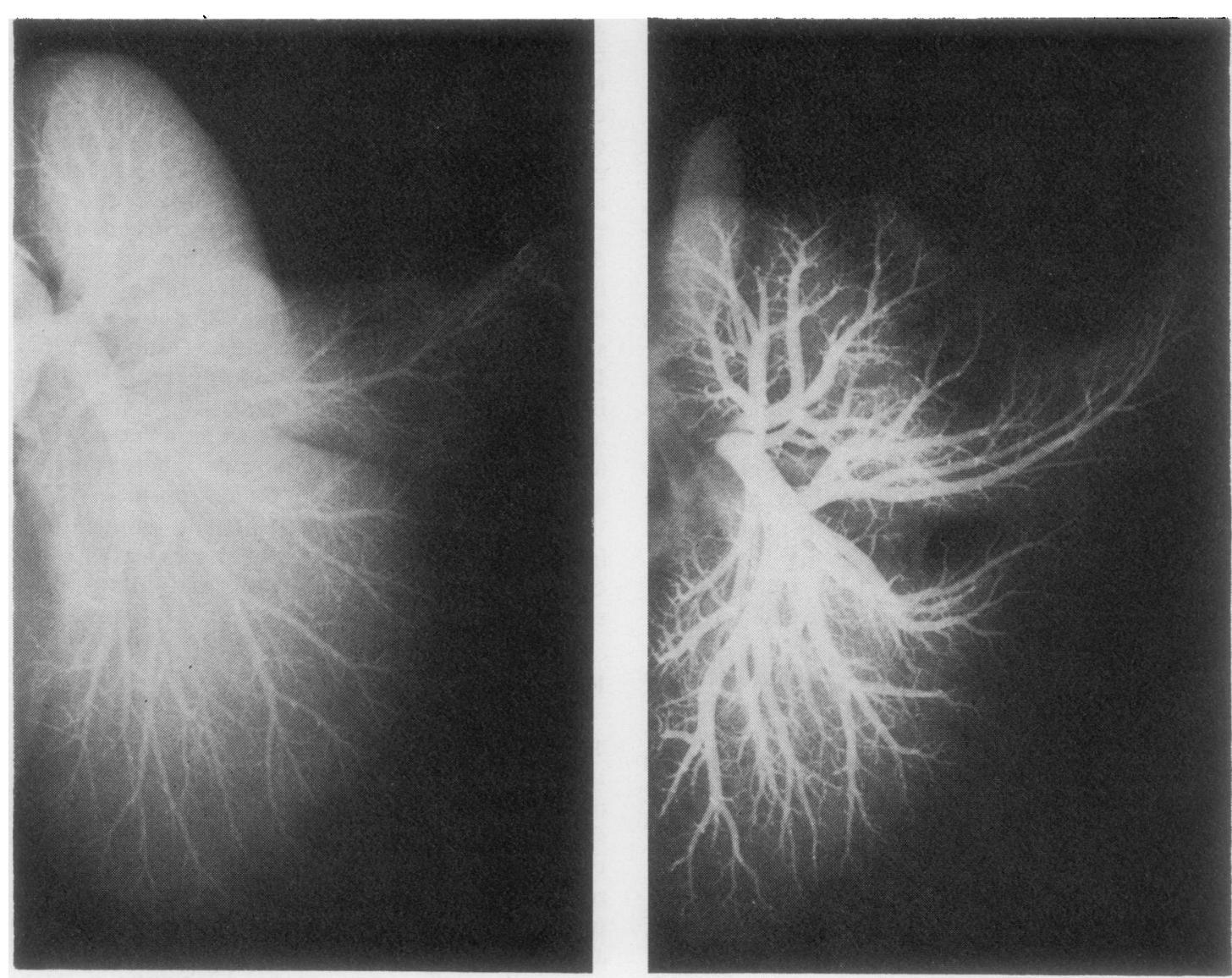

Fig. 1 Arteriogram of left lung in (left) a case of aortic atresia and (right) a normal infant showing an abnormal increase in density background haze in aortic atresia (×0.95).

Table 2 Number of alveoli and arteries per unit area and alveolar/arterial ratio

\begin{tabular}{lcll}
\hline Case No. & $\begin{array}{l}\text { Alveoli } \\
(\text { No. })\end{array}$ & $\begin{array}{l}\text { Arteries } \\
(\text { No. })\end{array}$ & $\begin{array}{l}\text { Alveolar/Arterial } \\
\text { ratio }\end{array}$ \\
\hline 1 & 15324 & 1290 & $11 \cdot 8$ \\
2 & 14338 & 1001 & $14 \cdot 3$ \\
3 & 15884 & 812 & $19 \cdot 6$ \\
4 & 10931 & 782 & $14 \cdot 0$ \\
5 & 12467 & 556 & $22 \cdot 4$ \\
6 & 8860 & 408 & $21 \cdot 6$ \\
& & & \\
Normal values at: & 8863 & 468 & $18 \cdot 9$ \\
Birth & 12722 & 625 & $20 \cdot 3$ \\
3 days & 13196 & 516 & $25 \cdot 5$ \\
4 weeks & 11315 & 529 & $22 \cdot 2$ \\
4 months & & & \\
\hline
\end{tabular}

\section{Arterial muscularity}

All cases showed a considerable increase in muscularity as judged by medial thickness and by extension of muscle into smaller and more peri- pheral arteries than is normal (Fig. 2). In vessels $\delta$ of all sizes percentage wall thickness was higher than during fetal life (Hislop and Reid, 1972). 을 Surprisingly, the mean medial thickness was $\supset$ greater in the cases of aortic stenosis than in those of aortic atresia, perhaps because one case of $\mathrm{N}$ aortic stenosis, the infant, had survived for 21 \% days, time enough to develop considerable arterial ${ }^{N}$ muscularity, while one of the cases of aortic ${ }_{\mathrm{C}}^{N}$ atresia (case 2) had a secundum atrial septalo defect and therefore no obstruction to pulmonary

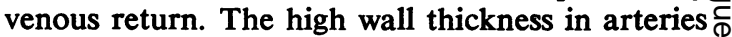
less than $250 \mu \mathrm{m}$ in diameter suggests that these $\stackrel{\oplus}{+}$ vessels did not dilate normally at birth (Hislop 0 and Reid, 1973a).

Examination of the structure of arteries accom- $\stackrel{\mathrm{D}}{\mathrm{Q}}$ panying peripheral airways showed considerable $\overrightarrow{\mathbb{Q}}$ extension of muscle along arterial pathways (Table $\frac{}{\sigma}$ 3 ). In the normal lung at birth few arteries within the acinus have a muscular coat. During child- $\frac{0}{0}$ 


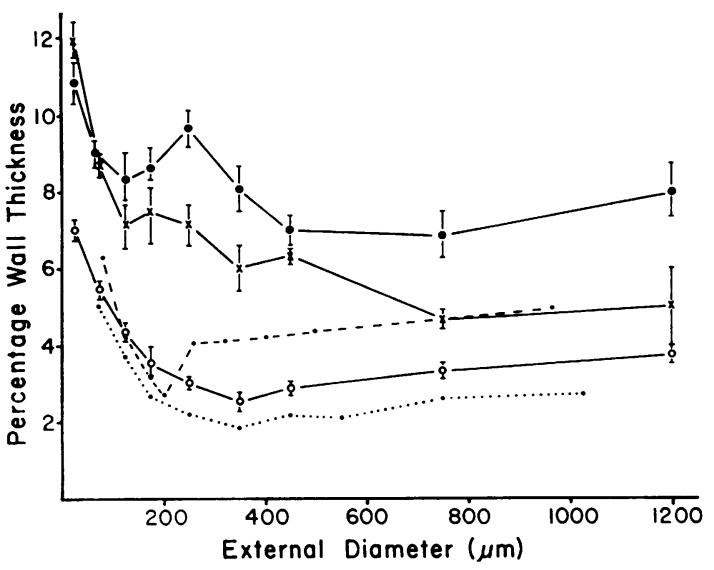

Fig. 2 Mean percentage wall thickness of small peripheral pulmonary arteries related to external diameter $(\mu \mathrm{m})$ showing increase in muscularity in cases of aortic atresia and stenosis, and in cases of coarctation a decrease in wall thickness in arteries greater than $250 \mu \mathrm{m}$ in diameter. $\longrightarrow$ Aortic stenosis. $\mathrm{x}-\mathrm{x}$ Aortic atresia. $\mathrm{c}-\mathrm{o}$ Coarctation PD.A and VSD. $\bullet-\bullet$ Normal 3 days. $\bullet . . . \bullet$ Mean of 6 normal children 10 months -10 years. I SE.

Table 3 Proportion of arteries of different structural types accompanying peripheral airways

\begin{tabular}{|c|c|c|c|c|}
\hline $\begin{array}{l}\text { Case } \\
\text { No. }\end{array}$ & $\begin{array}{l}\text { Structural } \\
\text { type }\end{array}$ & $\begin{array}{l}\text { Terminal } \\
\text { bronchioli }\end{array}$ & $\begin{array}{l}\text { Respiratory } \\
\text { bronchioli }\end{array}$ & $\begin{array}{l}\text { Alveolar } \\
\text { ducts }\end{array}$ \\
\hline \multirow[t]{3}{*}{1} & $\mathrm{~nm}$ & - & - & - \\
\hline & pm & - & 9 & 68 \\
\hline & $\mathrm{m}$ & 100 & 91 & 32 \\
\hline \multirow[t]{3}{*}{2} & $\mathrm{~nm}$ & \multirow{3}{*}{\multicolumn{3}{|c|}{$\begin{array}{l}\text { Consolidation made accurate } \\
\text { identification of peripheral airways } \\
\text { impossible }\end{array}$}} \\
\hline & pm & & & \\
\hline & $\mathbf{m}$ & & & \\
\hline \multirow[t]{3}{*}{3} & $\mathrm{~nm}$ & - & - & 28 \\
\hline & pm & - & 38 & 67 \\
\hline & $\mathbf{m}$ & 100 & 62 & 5 \\
\hline \multirow[t]{3}{*}{4} & $\mathrm{~nm}$ & - & - & 15 \\
\hline & $\mathrm{pm}$ & 20 & 64 & 85 \\
\hline & $\mathbf{m}$ & 80 & 36 & - \\
\hline \multirow[t]{3}{*}{5} & $\mathbf{n m}$ & - & - & 28 \\
\hline & pm & 75 & 100 & 72 \\
\hline & $\mathrm{m}$ & 25 & - & - \\
\hline \multirow[t]{3}{*}{6} & $\mathrm{~nm}$ & - & 9 & 48 \\
\hline & pm & - & 78 & 52 \\
\hline & m & 100 & 13 & - \\
\hline \multicolumn{5}{|c|}{ Normal values (Hislop and Reid 1973a) at: } \\
\hline \multirow[t]{3}{*}{3 days } & $\mathrm{nm}$ & - & 30 & 66 \\
\hline & pm & 72 & 70 & 34 \\
\hline & m & 28 & - & - \\
\hline \multirow[t]{3}{*}{4 months } & $\mathrm{nm}$ & - & 3 & 35 \\
\hline & pm & - & 30 & 18 \\
\hline & $\mathbf{m}$ & 100 & 67 & 47 \\
\hline
\end{tabular}

$\mathrm{nm}=$ non-muscular $; \mathrm{pm}=$ partially muscular $; \mathrm{m}=$ muscular .

hood muscle gradually extends along the arterial pathway, reaching alveolar wall vessels in late adolescence (Hislop and Reid, 1973a). In all four of the present cases, however, over $65 \%$ of arteries accompanying alveolar ducts had a partially muscular wall and many alveolar wall arteries were completely muscularised.

The available venograms, one of a case of aortic atresia (case 2) and one of aortic stenosis (case 4), showed dilatation of the preacinar pathways. In all cases vein wall thickness was increased and an external elastic lamina had appeared. Thus, according to Wagenvoort's (1970) description, the veins had become 'arterialised'.

\section{COARCTATION OF AORTA WITH PDA AND VSD Arterial size}

In contrast to the cases of aortic atresia and stenosis, in both cases of coarctation with PDA and VSD the preacinar arterial lumen diameter and the external diameter of intra-acinar arteries at the level of the terminal bronchioli were greater than normal. The number of arteries per unit area of lung and the alveolar/arterial ratio were normal for the age of the child.

Arterial wall thickness was less than normal in vessels above $250 \mu \mathrm{m}$ in diameter (Fig. 2) perhaps because of dilatation. In smaller arteries wall thickness was normal. Within the acinus muscle extended into smaller and more peripheral arteries than is normal (Table 1). In the younger of the two infants (case 5) the appearance of the muscle cells present at alveolar duct level suggested immaturity. The cells were arranged as a single layer, the media were only $1.13 \mu \mathrm{m}-1.96 \mu \mathrm{m}$ thick, and they stained poorly, if at all. While $72 \%$ of arteries at alveolar duct level were partially muscular none was entirely muscular. The infant in case 6 was 12 days older than the infant in case 5 and the proportion of muscularised arteries was increased at all levels within the acinus: the muscle cells stained normally.

\section{Discussion}

In cases of both aortic atresia and stenosis there was an increase in number of the intra-acinar arteries and the arteries and veins were more muscular. The muscularity was shown both by an increase in wall thickness of normally muscular vessels and by extension of muscle into vessels that do not normally contain it at this age. Arterial size was generally normal. Since three of these babies died in the first three days of life these changes undoubtedly occurred before birth. In contrast, in coarctation of the aorta the preacinar pulmonary arteries were dilated and thin walled but muscle was found more peripherally than normal, since intra-acinar arteries had 
smooth muscle cells in their wall. In the youngest child the muscle cells were of immature appearance, suggesting development after birth. These structural differences probably reflect a difference both in haemodynamic abnormality and in the stage of fetal or postnatal life at which it developed.

\section{AORTIC ATRESIA AND STENOSIS}

The methods used in this study supplement the information obtained from previously used techniques. Wagenvoort and Edwards (1961), using uninjected tissue, demonstrated an increase in arterial medial muscle area per unit of lung tissue, which they thought was due to an increase in the number of muscularised arteries. Naeye (1962), using a planimetric technique, demonstrated an increase in medial muscle in individual vessels already muscularised, as we have also shown. Our results show that increase in the amount of muscle is due to an increase in muscle of arteries already muscularised and to an extension of muscle into arteries that are not normally muscularised. Furthermore, the number of peripheral arteries 'available' for muscularisation is also increased.

In the present study accurate measurements of diameter and wall thickness of individual arteries revealed not only the severity of medial hypertrophy but also that arteries smaller than $250 \mu \mathrm{m}$ in diameter had failed to dilate normally at birth. We have also demonstrated a normal preacinar branching pattern, the virtual absence of arterial dilatation, either pre- or intra-acinar, and an increase in arterial multiplication within the acinus.

Thus in aortic atresia and stenosis lung development has been affected before birth, presumably by the abnormal pattern of blood flow through the heart and great vessels. At birth the right ventricular pressure is abnormally raised, although opinions differ about the level of pulmonary arterial pressure before birth. Rudolph (1974) argues that pulmonary hypertension will develop in utero in this condition only if the ductus arteriosus fails to dilate to accommodate adequately the systemic blood flow; right ventricular pressure would then increase in an attempt to maintain systemic and placental perfusion. Our findings of increased pulmonary arterial muscularity suggest an abnormally high pulmonary arterial pressure before birth, despite the fact that in all cases the ductus arteriosus was large.

The prenatal development of arterial medial hypertrophy in aortic atresia and stenosis has previously been attributed either to pulmonary venous obstruction (Wagenvoort and Edwards,
$1961)$ or to a raised right ventricular pressure $\stackrel{\vec{\rho}}{\stackrel{9}{9}}$ (Naeye, 1962). Our results favoured pulmonaryo arterial hypertension as the cause. In the presento series medial hypertrophy was always greater than $\overline{\bar{c}}$ is usually seen in newborn infants with total $\vec{\phi}$ anomalous pulmonary venous return (personal $\stackrel{\varrho}{\sim}$ observation). Furthermore, the presence of vein ${ }^{\infty}$ wall hypertrophy does not necessarily imply.

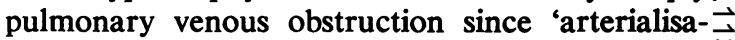
tion' of veins may occur in the presence of only ${ }_{\sigma}$ moderate pulmonary venous hypertension, as is $\vec{x}$ seen in VSD (Hislop et al., 1975).

The arterial medial hypertrophy favours $\stackrel{\omega}{N}$ diversion of blood away from the lungs, thus? ensuring adequate systemic perfusion. Muscle $\vec{\sim}$ hypertrophy encroaches on the lumen, and because 0 the arteries are smaller before than after birth an increase in size or number of muscle cells will $>$ produce a greater increase in resistance. At birth을 pulmonary vascular resistance must have fallen $\overrightarrow{\vec{\theta}}$ slightly but the high wall thickness of small pulmonary arteries found in the lungs of these. newborn infants suggests that they did not dilate normally at birth, and so a raised pulmonary vascular resistance is maintained.

This discussion implies that the smooth muscle ֶ hypertrophies in response to haemodynamic $\stackrel{\perp}{\varrho}$ changes in the pulmonary circulation and is not $a_{\vec{O}} \overrightarrow{\vec{O}}$ primary structural abnormality. In older children 3 with pulmonary hypertension there is an increase $?$ in muscularity of both pre- and intra-acinar: arteries, as here, while in newborn children with persistent pulmonary hypertension (without con-을 genital heart disease) it is only the intra-acinar arteries which are affected (Haworth and Reid, $\frac{0}{7}$ 1976). A prenatal increase in number of intraacinar arteries has not previously been reported. $\delta$ This increase could include some peripheral pre- $₹$ acinar arteries, since at this level such vessels $ᄋ$ would be included in the arterial count of small $>$ arteries. Vessel number in post-natal life is influenced by haemodynamic changes, increasing in N tetralogy of Fallot (Hislop and Reid, 1973b) and decreasing in VSD (Hislop et al., 1975). In the $\widetilde{N}$ present study the mechanism responsible for the $\tilde{\omega}$ excessive multiplication of intra-acinar arteries is not understood, but the multiplication must occurco some time before birth since at birth these vessels $\mathbb{\mathbb { D }}$ are surrounded by a thick coat of mature muscle $\stackrel{\oplus}{+}$ cells. The simplest interpretation is that it is a response to increased flow.

The development of an increased number of $\stackrel{\overparen{D}}{\stackrel{D}{Q}}$ arteries would increase the number of vessels avail- $\mathbb{\mathbb { Q }}$ able for recruitment. If the distensibility of the peripheral arteries is reduced by muscle hypertrophy recruitment of peripheral arteries may be응 
important in accommodating the increase in pulmonary blood volume occurring at birth. Recruitment of additional channels is thought to be more important than distension in accommodating an increase in blood volume (Maseri et al., 1972).

\section{COARCTATION OF AORTA WITH PDA AND VSD}

In both cases of coarctation with PDA and VSD there was no increase either in the number of intra-acinar arteries or in arterial wall thickness, suggesting that, unlike cases of aortic atresia and stenosis, the structure of the pulmonary circulation was probably normal at birth. This supports the contention that coarctation can develop after birth, arising when the aortic end of the ductus arteriosus constricts after birth and protrudes slightly into the lumen of the aorta, approaching a shelf of tissue on the posterolateral surface of the aortic wall (Rudolph et al., 1972). Had aortic obstruction been present before birth severe medial hypertrophy, similar to that seen in the present cases of aortic atresia and stenosis, would have been expected even in the 5-day-old child. When infants are born with severe coarctation an increase in arterial wall thickness may be found, as in the cases reported by Naeye (1961).

Reduction in wall thickness of small arteries under $250 \mu \mathrm{m}$ in diameter suggests that pulmonary vascular resistance had fallen normally at birth, permitting a left-to-right shunt across the PDA and VSD. The muscle cells found in vessels under $250 \mu \mathrm{m}$ in diameter had almost certainly appeared after birth, probably in response to the secondary increase in arterial pressure caused by a PDA and VSD. In the older infant considerable muscle hypertrophy had developed by 17 days of age.

Although it has been suggested that regression of pulmonary arterial muscle after birth is delayed in the presence of an aortopulmonary communication (Hoffman and Rudolph, 1965), our results offer evidence that wall thickness of small arteries can diminish normally during the first few days of life but that subsequently the development of new muscle cells occurs rapidly. At 5 days of age immature muscle cells were seen. In the experimental animal they may be detected after only three days exposure to hypoxia (Hislop, personal communication). Possibly the rapidity with which muscle cells develop has previously been underestimated, and in some cases of congenital heart disease early formation of muscle cells may have been mistaken for persistence of fetal muscle.

Thus it seems that in aortic atresia and stenosis the entire cardiac output is ejected by the right ventricle into the pulmonary artery and the pulmonary arterial smooth muscle hypertrophies. Pulmonary vascular resistance is thereby increased and systemic perfusion encouraged. This haemodynamic state persists after birth and peripheral pulmonary arteries remain thick walled. The mechanism of production and the functional effects of the excessive multiplication of intraacinar arteries remain unexplained. By contrast, when coarctation develops after birth the pulmonary circulation is structurally normal in utero. At birth pulmonary arterial pressure falls normally and the small vessels dilate, permitting a left to right shunt to develop across the PDA and VSD. As pulmonary blood flow increases the arteries dilate and then, as pulmonary arterial pressure increases, their muscle coats hypertrophy.

Aortic atresia and stenosis may increase the lungs' susceptibility to vasoconstrictor agents such as hypoxia and acidosis. The rapid postnatal increase in muscularity in the presence of pulmonary hypertension suggests that if the structure of the pulmonary circulation were the only consideration it would be better not to delay surgical intervention.

We thank the physicians and surgeons of the Brompton Hospital, London, and the Deutsches Herzzentrum, Munich, Germany, for permission to use material from their cases.

This work was supported by the Wellcome Trust.

\section{References}

Anderson, E. G., Simon, G., and Reid, L. (1973). Primary and thrombo-embolic pulmonary hypertension: a quantitative pathological study. Journal of Pathology, 110, 273-293.

Davies, G. and Reid, L. (1970). Growth of the alveoli and pulmonary arteries in childhood. Thorax, 25, 669-681.

Dunnill, M. S. (1962). Quantitative methods in the study of pulmonary pathology. Thorax, 17, 320328.

Ferencz, C. and Dammann, J. F. Jr. (1957). Significance of the pulmonary vascular bed in congenital heart disease. V. Lesions of the left side of the heart causing obstruction of the pulmonary venous return. Circulation, 16, 1046-1056.

Haworth, S. G. and Reid, L. (1976). Persistent fetal circulation: Newly recognized structural features. Journal of Pediatrics, 88, 614-620.

Hislop, A., Haworth, S. G., Shinebourne, E. A., and Reid, L. (1975). Quantitative structural analysis of pulmonary vessels in isolated ventricular septal defect in infancy. British Heart Journal, 37, 10141021. 
Hislop, A. and Reid, L. (1970). New pathological findings in emphysema of childhood: 1. Polyalveolar lobe with emphysema. Thorax, 25, 682-690.

Hislop, A. and Reid, L. (1972). Intra-pulmonary arterial development during fetal life-branching pattern and structure. Journal of Anatomy, 113, 35-48.

Hislop, A. and Reid, L. (1973a). Pulmonary arterial development during childhood: branching pattern and structure. Thorax, 28, 129-135.

Hislop, A. and Reid, L. (1973b). Structural changes in the pulmonary arteries and veins in tetralogy of Fallot. British Heart Journal, 35, 1178-1183.

Hoffman, J. I. E. and Rudolph, A. M. (1965). The natural history of ventricular septal defects in infancy. American Journal of Cardiology, 16, 634 653.

Maseri, A., Caldini, P., Harward, P., Joshi, R. C., Permutt, S., and Zierler, K. L. (1972). Determinants of pulmonary vascular volume: recruitment versus distensibility. Circulation Research, 31, 218-228.

Naeye, R. L. (1961). Perinatal vascular changes in coarctation of the aorta with distal patent ductus arteriosus. Circulation, 24, 754-760.

Naeye, R. L. (1962). Perinatal vascular changes associated with underdevelopment of the left heart. American Journal of Pathology, 41, 287-295.
Rudolph, A. M. (1974). In Congenital Diseases of the Heart, p. 552. Year Book Medical Publishers, New York, Chicago.

Rudolph, A. M., Fishman A., and Heymann, M. A. (1974). Cited by Rudolph, A. M. In Congenital Diseases of the Heart, pp. 363 and 548. Year Book Medical Publishers, New York, Chicago.

Rudolph, A. M., Heymann, M. A., and Spitznas, U. (1972). Hemodynamic considerations in the development of narrowing of the aorta. American Journal of Cardiology, 30, 514-525.

Samuelson, A., Becker, A. E., and Wagenvoort, C. A. (1970). A morphometric study of pulmonary veins $x$ in normal infants and infants with congenital heart disease. Archives of Pathology, 90, 112-116.

Wagenvoort, C. A. (1970). Morphologic changes in the intrapulmonary veins. Human Pathology, 1, 205-213.

Wagenvoort, C. A. and Edwards, J. E. (1961). The pulmonary arterial tree in aortic atresia with intact ventricular septum. Laboratory Investigation, 10, 음 924-933.

Requests for reprints to: Dr. Lynne Reid, Department of Pathology, Bldg. G-9, Children's Hospital Medical Center, 320 Longwood Avenue, Boston, Ma 02115, U.S.A. 